\title{
REFUGEE MERCY MISSION IN LEBANON
}

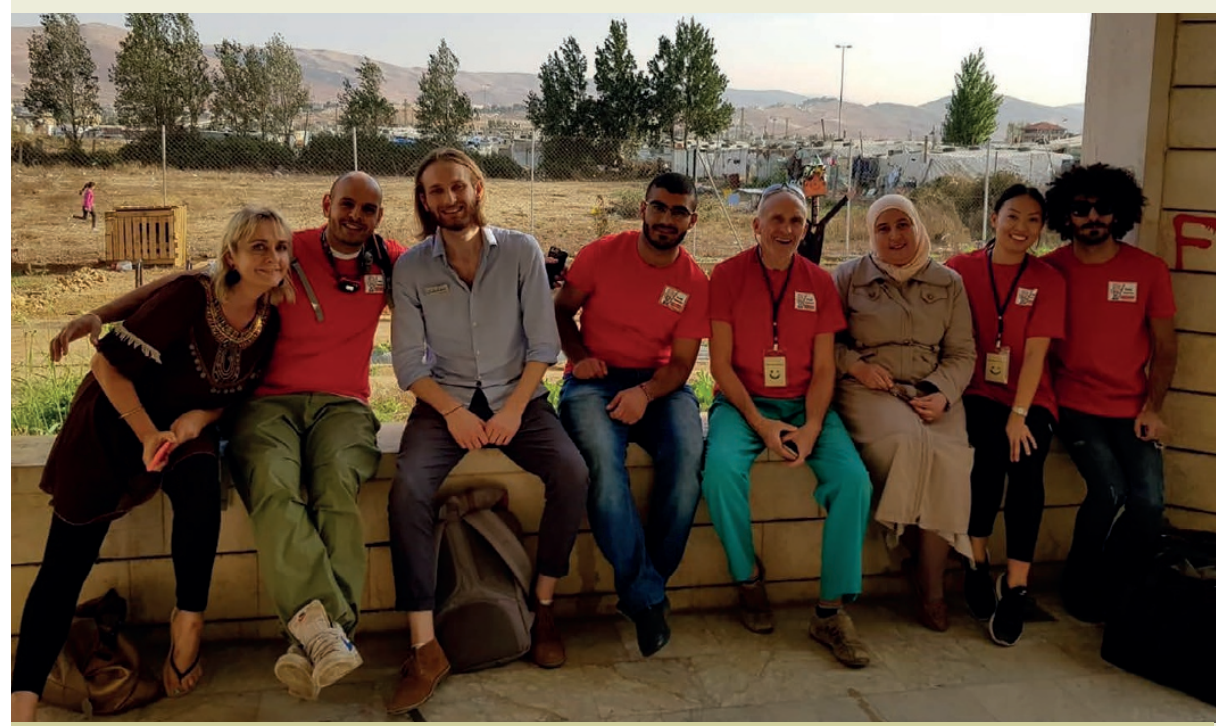

Dr Gautam Sharma, second from left, Principal dentist of the West Earlham Dental Practice, Norfolk with his team, on left, Sebastian Lundby, field coordinator, and then left to right, Omar Merie, translator, Graham Temple, dentist, Basima M Amin, local translator and clinic manager, Rachael Tsang, dental therapist, Hasan Merhi, translator.

Gautam Sharma, who runs West Earlham Dental Practice, is a trustee of the Dental Mavericks Charity, and formed part of an international contingent of 50 dentists, healthcare assistants, translators and cultural advisors who spent five days in Lebanon.

Thanks to the generosity of people in East Anglia, he was able to take with him a haul of gifts and supplies. He said: 'This was my second trip to the region, so I had some idea of what to expect this time, but even so, I don't think I was quite prepared for the relentless pace of the number of patients coming through to be seen.

'We started early each morning and finished late into the evening, every day treating close to 300 Syrian and Lebanese children. I was heartened to see that we were making less extractions than on our previous visit, but still the need is high, and we were welcomed with open arms and treated with huge gratitude by every single patient,' he added.

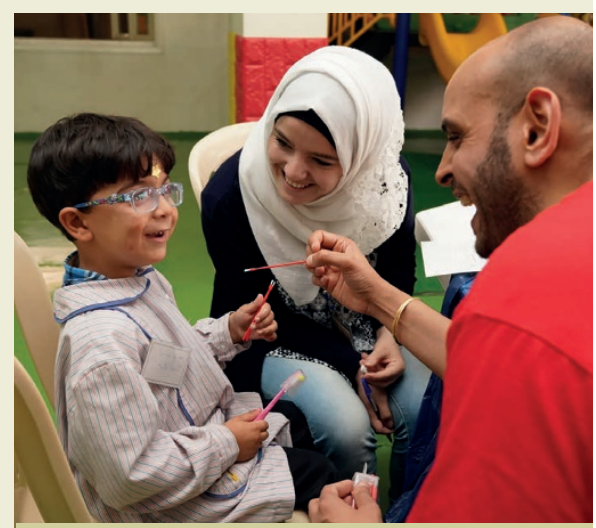

Dr Gautam Sharma with a young patient and his mother.

\section{THE BIG TEES SLEEPOUT \\ Team members from Vitality Dental, part of the Alpha Dental Group, raised more than £1k by sleeping out in Middlesbrough to raise money for the Teesside Philanthropic Foundation. 'The Big Tees Sleepout' saw hundreds of people sleep rough for the night to raise awareness and vital funds to help those facing homelessness and poverty. Despite a wet and windy night, the team from Vitality Dental remained in high spirits. Any further donations would be greatly appreciated by the Teesside Philanthropic Foundation at www.justgiving.com/fundraising/elle-maxwell}

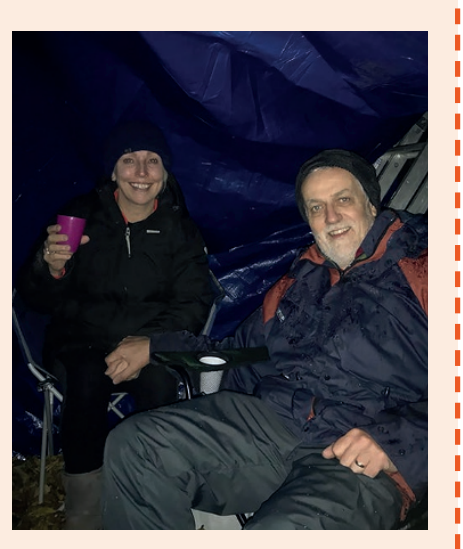

\section{Whistleblowing}

The General Dental Council received more whistleblowing disclosures in 2017-18 than any of the eight healthcare regulators. Since April 2017, a new legal duty came into force which required all prescribed

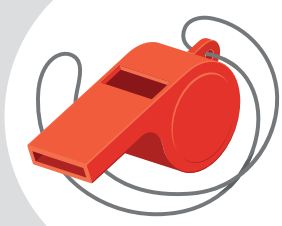
bodies to publish an annual report on the whistleblowing disclosures made to them by workers and the new joint report highlights the regulators' coordinated effort to work together in handling serious issues.

The Whistleblowing disclosures report $2018^{1}$ details cases from the GDC, General Medical Council (GMC), Nursing \& Midwifery Council (NMC), General Chiropractic Council, General Optical Council, General Osteopathic Council, General Pharmaceutical Council, and Health \& Care Professions Council.

It shows that between 1 April 2017 and 31 March 2018, the GDC received three times the number received by fellow regulator, the GMC, which accumulated 23 cases. The majority of disclosures were made direct to the GDC's Fitness to Practise (FtP) team and led to regulatory action. In addition, two disclosures were made during this period relating to education providers. One disclosure related to a course provider where the GDC was already undertaking regulatory action. The second disclosure resulted in a number of FtP cases relating to clinical concerns being opened and investigated.

In the report, a GDC spokesperson acknowledged the higher number of whistleblowers compared with many of the other regulators and said this could be due to how dental care was provided.

'While we are unable to form firm conclusions as to why this might be the case, it is worth noting that most dentistry is provided in a primary care setting and outwith the more robust clinical governance frameworks that characterise some other forms of healthcare.'

'This may mean that alternative disclosure routes are less present in dentistry, and a larger proportion are dealt with by the regulator. We may be able to explore this further as we collect more data.'

1. Whistleblowing disclosures report 2018 (11 September 2018). https:// www.gmc-uk.org/-/media/documents/ whistleblowing-report-2018_pdf75910452.pdf (accessed on 18 September 2018). 